\title{
Problem Solving in Mathematics and Students' Attitudes towards a Humanistic Approach
}

\author{
Suhandri*, Yaya S. Kusumah, Turmudi, Dadang Juandi \\ Department of Mathematics Education, Universitas Pendidikan Indonesia, Jl. Dr. Setiabudhi No. 229, Bandung, \\ West Java, 40154, Indonesia
}

Received January 17, 2021; Revised March 8, 2021; Accepted March 23, 2021

\begin{abstract}
Cite This Paper in the following Citation Styles
(a): [1] Suhandri, Yaya S. Kusumah, Turmudi, Dadang Juandi, "Problem Solving in Mathematics and Students' Attitudes towards a Humanistic Approach," Universal Journal of Educational Research, Vol. 9, No. 5, pp. 1064 - 1071, 2021. DOI: 10.13189/ujer.2021.090519.
\end{abstract}

(b): Suhandri, Yaya S. Kusumah, Turmudi, Dadang Juandi (2021). Problem Solving in Mathematics and Students' Attitudes towards a Humanistic Approach. Universal Journal of Educational Research, 9(5), 1064 - 1071. DOI: 10.13189/ujer.2021.090519.

Copyright $\odot 2021$ by authors, all rights reserved. Authors agree that this article remains permanently open access under the terms of the Creative Commons Attribution License 4.0 International License

\begin{abstract}
Anxiety and fear are the main sources of student failure to accept mathematics learning and impact their inability to solve mathematical problems that require concentration, persistence, and seriousness. This study aims to: (1) Examine the improvement of students' mathematical problem-solving abilities through humanistic approaches and direct learning based on learning and at the school level; (2) Determine whether there is an interaction between learning (humanistic approach, direct learning) and the school level (moderate, low) on improving mathematical problem-solving abilities; (3) Students' attitudes towards the humanistic approach. This research method is quasi-experimental using the nonequivalent control-group design. The population in this study was students of class VIII MTs in Pekanbaru City, and the sample was students in two classes at each different school level, totaling 120 students. The instrument used consisted of problem-solving test questions. The conclusions obtained in this study are: (1) The overall achievement of the mathematical problem-solving ability of students who take learning with a humanistic approach is better than students who take direct learning. There are differences in the increase in problem-solving of students who take the humanistic approach and students who take direct learning; (2) The best quality in improving students' mathematical problem-solving abilities in the two learning groups is at the medium school level; (3) There is no interaction between learning (humanistic approach, direct learning) and the school level (moderate, low) on improving mathematical problem-solving abilities; (4) Learning with
\end{abstract}

a humanistic approach raises a positive attitude: courageous, active and creative in students and able to work well among fellow students.

Keywords Humanistic Approach, Problem-Solving Ability, Student Attitude

\section{Introduction}

In Indonesia, the problem that is often faced by a teacher in providing mathematics learning is the hidden rejection of students towards mathematics as a result of anxiety in the form of feelings of tension, worry, or fear that interferes with students' math performance. They assume that the math learned in school is useless in their lives, always dealing with meaningless numbers and symbols that traumatize them, making them feel depressed about understanding mathematics. Simmers [1] said that many students stated that mathematics was not easy to understand. This was confirmed by the Organization for Economic Co-operation and Development (OECD) in the results of a 2012 study, in 34 countries that participated in OECD, $59 \%$ of students aged 15 to 16 reported that they often worry about maths that will make it difficult for them; $33 \%$ reported that they became agitated when it came to completing math homework; and $31 \%$ stated that they are very nervous about doing math problems [2].

Anxiety and fear have been the main sources of 
students' failure to accept mathematics learning, which requires concentration, perseverance, and seriousness in following it. Likewise, when students make mistakes, teachers do not provide assistance or inadequate assistance. They can develop a mindset that is erroneously and permanently hinder learning and have long-term consequences, and equate their mistakes with their lack of ability to think logically, critically, and solve problems [3], [4]. Many students admit that their emotional attitudes towards mathematics and their academic performance change when attitudes toward mathematics teachers change.

Problem-solving is an integral part of all mathematics learning and should not be an isolated part of the mathematics program [5]. Students must possess the problem-solving ability because it is one of the goals of mathematics education and is indispensable for every student because it is related to students' readiness in the real world. Students accustomed to facing problems in a lesson can prepare mentally better in dealing with problems in their future. Problem-solving is an important part of individual success and future life and life work in the 21st century [6]. However, many students are unable to solve problem-solving, as revealed by the findings of the Program for International Student Assessment (PISA) [7], which states that students in Indonesia have very little mastery of mathematical problem-solving skills, while solving-problem is abilities that are useful for each individual as a provision for them to face challenges in the 21st century.

Problem-solving is the student's first step in developing ideas, building new knowledge, and developing math skills. As stated in the National Council of Teachers of Mathematics [5], all students will design and build new mathematical knowledge through problem-solving. The error factors that often occur in students in problem-solving are they cannot absorb information well, do not understand problem transformations, and are weak in understanding mathematical concepts [8]. Thus the students' mathematical problem-solving abilities are in low qualifications.

Minimizing student anxiety about mathematics and fostering problem-solving abilities includes mathematics in their lives with humanistic recognition designed and packaged in a learning approach that makes students involved in it so that the learning carried out becomes meaningfully enjoyable. Many students agree that if the teacher provides learning with attractiveness, smiles, and is kind, students' mistakes are wisely addressed, students will get satisfaction and joy during the time spent in learning mathematics, and will create positive motivation for mathematics acquisition [9]. Therefore, strong emphasis can be placed on developing mathematics learning in life-long educational programs. Appropriate teaching methods characterize good learning, and priority can be given to teachers to increase teachers' capacity and professional competence to apply appropriate teaching methods to improve student competence.

Thus the main obstacle to learning mathematics is not a cognitive factor, nor is it a factor of students not wanting to learn but do not want to learn. If educators invest a fraction of the energy they are currently spending on transmitting information to stimulate student excitement in learning, they can achieve better results. Haglund [10] states that one of the most promising options for improving mathematics education at all levels is the "humanistic" approach proposed by Dr. Alvin White of Harvey Mudd College in Claremont, CA.

Some of the general characteristics of the "humanistic" class may include:

- Putting students in the position of investigators, not just receptors for facts and procedures;

- Allowing students to help each other understand problems and solutions more deeply;

- Learning many ways to solve problems, not just an algebraic approach;

- Using interesting problems and open-ended questions;

- Using a variety of assessment techniques, not only assessing a student on his or her ability to perform memorized procedures;

- Developing an understanding and appreciation of some of the great mathematical ideas that have shaped our history and culture;

- Helping students view mathematics as a study of patterns, including aspects such as beauty and creativity;

- Helping students develop an attitude of independence and curiosity.

That is why the importance of the humanistic learning process, which means approaching the content of mathematics education and its acquisition using humanistic recognition principles, taking into account the interests, abilities, and insights of students. Thus, it is hoped that the humanistic approach can develop self-values, self-efficacy, self-reflection, and, at the same time, increase their ability to solve problems and master mathematics fully, and accept others' awareness needs.

\section{Literature Review}

\subsection{Humanistic Approach}

The humanistic approach to mathematics learning is based on humanism principles, especially in Abraham Maslow's (1908-1970) and Carl Rogers (1902-1987). The humanistic approach is centered on the student as the individual. It assumes that learning is about intelligence and about educating the "whole person," taking into account one's interests, goals, and enthusiasm so that students' full potential can be achieved [11]. 
Incorporating humanistic elements in educational practice will enable an educator to help students develop teamwork, problem-solving, system improvement, and lifelong learning [12]. Therefore the focus is on the teacher's ability to cultivate a strong self-concept in students and make personal decisions and a strong belief in independent learning. Humanistic educators have a broad understanding of students' knowledge as they grow and highly value students' social and affective development and intellectual development. Learners are encouraged to be responsible for their own learning and are intrinsical, not extrinsically motivated. The humanist approach to learning mathematics supports positive emotions in students (motivation, self-confidence, empathy, and high self-esteem) and tries to avoid negative emotions (anger, anxiety, stress, and depression) [11].

Humanistic education aims to contribute to developing an energetic, positive, self-respecting, and caring human who can meet all challenges. So that learning becomes actualized with intrinsic motivation towards achievement. Students can adapt previous knowledge to new experiences. Besides, education will be effective when it is in line with the natural tendencies of students. Students will become active participants in their education, taking responsibility for their own learning, even participating in the planning, implementing, and evaluating their own learning [13]. Thus humanistic education can enhance learning by making personal connections with students' lives, emotions, and experiences. So that students learn more and learn more deeply [14].

\subsection{Problem-Solving Skills}

Problem-solving is a fundamental means of developing students' mathematical knowledge by training them-selves to think and is one aspect that is very useful in their future lives. According to NCTM, problem-solving means engaging in a task for which the solution process is unknown. To find solutions, students must use their knowledge, and through this process, they will often develop new mathematical understandings [5]. Developing thinking skills are problem-based learning, critical thinking skills, creative thinking skills, decision making, conceptualization, and information processing [15].

Polya argues that problem-solving is an activity that humans always experience. Moreover, part of human conscious thinking is related to problems [16]. In theory and practice problem-solving, it requires a broad perspective to analyze problems to find the right solution [17]. According to [18], problem-solving uses certain heuristic steps to solve a problem. From the experts' viewpoint, problem-solving is a process to solve a problem using deep thoughts and a broad view with certain steps to find the right solution.

Problem-solving provides students with the context to help them understand more deeply the mathematical concepts they are learning. Problem-solving is useful for introducing new concepts to students and expanding the knowledge they learn. Problem-solving experiences should be integrated into real-life problem situations to build students' curiosity. Mathematical ideas can be developed around the problems raised by teachers and students. The teacher motivates students to explore, take risks, share failures and successes, and ask questions between students and teachers to establish good communication. Also, teachers need to appreciate students' thoughts and efforts when they develop strategies for overcoming problems.

\section{Method}

This research is using the experimental method. An experimental study involves independent variables applied to a particular group to see their effect on the dependent variable [19]. In this case, the independent variable is learning with a humanistic approach applied to the experimental group, while the dependent variable is the mathematical problem-solving ability under study. The implementation of research is in secondary schools.

This research was conducted in two schools with different levels, namely the medium-level and the low-level determination of school level based on school accreditation and average national examinations scores in the last two years. Simultaneously, the sample selected as the experimental group and the control group in each school used the purposive sampling technique.

The population in this study were all students of class VIII Madrasah Tsanawiyah in Riau, with a sample of 120 students. The sample distribution can be seen in Table 1 below.

Table 1. Sample Distribution based on School Level

\begin{tabular}{|c|c|c|}
\hline School Level & Group & Sample Size \\
\hline \multirow{2}{*}{ medium } & Experiment & 30 \\
\cline { 2 - 3 } & Control & 30 \\
\hline \multirow{2}{*}{ low } & Experiment & 30 \\
\cline { 2 - 3 } & Control & 30 \\
\hline \multicolumn{2}{|c|}{ whole } & 120 \\
\hline
\end{tabular}

A comprehensive study in this study reveals and analyzes the effect of learning factors on improving students' mathematical problem-solving abilities in two schools at medium and low levels. The learning factor, namely learning with a humanistic approach $(\mathrm{PH})$ and direct learning (PL), is an independent variable. Mathematical problem-solving ability (PM) is the dependent variable.

The instruments used in this study were tests and non-tests. The test instrument consists of questions related to mathematical problem-solving abilities, while the non-test instrument is a scale of students' attitudes towards the humanistic learning approach. 


\section{Data Analysis and Research Findings}

Research results and discussion are closely related to the research objectives. Likewise, data analysis results are used to reveal and analyze the increase in mathematical problem-solving abilities that follow learning with a humanistic approach.

\subsection{Ability to Solve Mathematical Problems}

After the mathematical problem ability test is carried out, the results are obtained in pretest and posttest scores. To determine the increase in students' mathematical problem abilities, it can be seen from the results of the pretest, posttest, and gain calculated based on the normalized gain formalized by Meltzer [20]. The test questions consist of 5 items in the form of descriptions with the material presented about the flat side room shape. In order to obtain a more detailed description of the data on the increase in problem-solving abilities, the following is a description of the data for the pretest, posttest, and increase in problem-solving abilities based on learning, school level, which can be seen in Table 2 .

Table 2. provides information that overall, the average increase in the problem-solving ability of students who take $\mathrm{PH}$ is higher than students who take PL, with the average difference of increase reaching 0.06 , while the improvement criteria for both are at a moderate level. The mean posttest score of students' PM ability who took PH was higher than students who took PL (the difference in mean posttest was 3.33) with a more diverse distribution.

Besides, the average increase in PM students' ability can also be seen from the division of school levels, namely the middle school level, and the low school level. For low school level students who follow $\mathrm{PH}$, the mean increase in their PM ability is higher than students who take PL with the criteria for improvement at a moderate level. However, for low school level students, the average increase in the PM ability of students who took PH was lower than students who took PL with the improvement criteria being at a low level. In Table 3, the data descriptions for the pretest, posttest, and the improvement of students' mathematical problem-solving abilities based on learning and school level are presented in Table 3.

It can be seen in Table 3, before the implementation of learning, the pretest mean of students who took $\mathrm{PH}$ was not much different from students who took PL at each school level. The pretest means difference was 0.06 and 1.80 , respectively. However, after learning, it was seen that the average post-test of students who took $\mathrm{PH}$ was higher than students who took PL at the moderate school level, with the difference reaching 3.57. Likewise, at the low school level, the post-test average of students who took PH was higher than students who took PL with a difference of 3.0 .

Judging from the average achievement of PM students who take $\mathrm{PH}$ at the moderate school level is 36.47 (an increase of 0.68). For students who take PL, the average achievement is only 32.9 (an increase of 0.60), a wider distribution. Big occurred in the group of students who attended PH. However, when viewed from the average PM achievement of students who took $\mathrm{PH}$ at the low school level of 34.5 (an increase of 0.64 ), the mean score for the achievement of PM students who took PL was 31.5 (increased by 0.59 ) with the distribution smaller data than students who attended $\mathrm{PH}$.

Table 2. Data Description of the Pretest, Posttest, and N-Gain of Problem-solving Ability based on Learning

\begin{tabular}{|c|c|c|c|c|c|c|}
\hline \multirow{2}{*}{ Statistics } & \multicolumn{3}{|c|}{ Learning with a Humanistic Approach (PH) } & \multicolumn{3}{|c|}{ Direct Learning (PL) } \\
\hline & Pretest & Posttest & N-Gain & Pretest & Posttest & N-Gain \\
\hline $\max$ & 12 & 43 & 0.82 & 12 & 40 & 0.74 \\
\hline $\min$ & 1 & 25 & 0.49 & 0 & 24 & 0.48 \\
\hline $\bar{x}$ & 6.85 & 35.53 & 0.66 & 5.98 & 32.20 & 0.60 \\
\hline$s$ & 2.3 & 3.29 & 0.02 & 2.68 & 3.33 & 0.014 \\
\hline \multicolumn{7}{|c|}{ Ideal Maximum Score: 50} \\
\hline
\end{tabular}

Table 3. Data Description of the Pretest, Posttest, and N-Gain of PM Ability based on Learning and School Level

\begin{tabular}{|c|c|c|c|c|c|c|c|}
\hline \multirow{2}{*}{ School Level } & \multirow{2}{*}{ Statistics } & \multicolumn{3}{|c|}{ Learning with a Humanistic Approach } & \multicolumn{3}{|c|}{ Direct Learning (PL) } \\
\hline & & Pretest & Posttest & $N$-Gain & Pretest & Posttest & $N$-Gain \\
\hline \multirow{4}{*}{ medium } & $\max$ & 12 & 43 & 0.82 & 12 & 38 & 0.68 \\
\hline & $\min$ & 2 & 29 & 0.56 & 2 & 29 & 0.56 \\
\hline & $\bar{x}$ & 7.17 & 36.47 & 0.68 & 7.23 & 32.9 & 0.60 \\
\hline & $s$ & 2.28 & 2.82 & 0.01 & 2.33 & 2.45 & 0.003 \\
\hline \multirow{4}{*}{ low } & $\max$ & 10 & 40 & 0.75 & 10 & 40 & 0.75 \\
\hline & $\min$ & 1 & 25 & 0.49 & 0 & 24 & 0.48 \\
\hline & $\bar{x}$ & 6.53 & 34.5 & 0.64 & 4.73 & 31.5 & 0.59 \\
\hline & $s$ & 2.32 & 3.44 & 0.02 & 2.43 & 3.95 & 0.03 \\
\hline \multicolumn{8}{|c|}{ Ideal Maximum Score: 50} \\
\hline
\end{tabular}




\subsection{Increased Ability to Solve Problems Based on Overall}

The research hypotheses tested in this section are: Overall, the improvement of students' mathematical problem-solving abilities who take learning with a humanistic approach is better than students who take direct learning. The results of testing the above hypotheses are presented in Table 4 .

Table 4. Summary of the Mann Whitney Test Differences in the Improvement of problem-solving Ability based on Overall

\begin{tabular}{|c|c|c|c|c|}
\hline \multirow{2}{*}{ Learning } & \multirow{2}{*}{$\begin{array}{c}\text { Comparison } \\
\text { of mean PH } \\
\text { and PL }\end{array}$} & \multicolumn{2}{|c|}{ Statistic test } & \multirow{2}{*}{ conclusion } \\
\cline { 3 - 4 } & $\begin{array}{c}\text { Mann- } \\
\text { Whitney }\end{array}$ & $\begin{array}{c}\text { Asymp.Sig } \\
\text { (2-tailed) }\end{array}$ & \\
\hline PH: PL & $35.53: 32.20$ & 823.00 & 0,000 & Reject $\mathrm{H}_{0}$ \\
\hline
\end{tabular}

It can be seen in Table 4 that the sig. $=0.000<\alpha=0.05$, which means that the hypothesis is rejected. Overall, there is a significant difference in the mean increase in the problem-solving ability of students who take $\mathrm{PH}$ and students who take PH.

\subsection{Increased Problem Solving Ability Based on Learning and School Level}

The statistical test used to test for differences in the improvement in mathematical problem-solving abilities is the Mann-Whitney test. The results of testing the above hypotheses are presented in Table 5 .
The mean increase in students' PM ability who take the humanistic approach and students who take direct learning at the medium and low school levels is 0.06 and 0.09 . After testing the difference between the two means using the Mann-Whitney nonparametric test at medium and low school levels, the results show the value of Sig. $<\alpha=0.05$, which means that the null hypothesis is rejected, meaning a significant difference between the two learning groups at medium and low school levels. This shows that the average increase in mathematical problem-solving abilities of students who follow the humanistic approach is better than students who take direct learning at the medium and low school levels.

\subsection{The Effect of Learning Interaction and School Level on the Improvement of Mathematical Problem Solving Ability}

One of this study's objectives is to see the interaction between the independent and control variables on the dependent variable. The test tool used is the Two Way ANOVA test through the General Linear Model. Processing of the average improvement in solving mathematical problems is carried out using the two-way Anova test. The results can be seen in Table 6 .

From Table 6, it can be seen that the value of Sig. $>\mathrm{A}=$ 0.05 . This means that there is no interaction between learning and the school level on improving students' mathematical problem-solving abilities. To reinforce the above statement, it can be seen in the graph of the interaction effect in Figure 1 below.

Table 5. Summary of the Mann-Whitney Test Differences in PM Ability Improvement based on Learning and School Level

\begin{tabular}{|c|c|c|c|c|}
\hline \multirow{2}{*}{ School Level } & Learning & $\begin{array}{c}\text { Comparison of Average } \\
\text { Improvement }\end{array}$ & \multicolumn{2}{|c|}{ Statistical Test } \\
\cline { 3 - 5 } & cH : PL & $0.66: 0.60$ & 144.50 & $\begin{array}{c}\text { Asymp.Sig } \\
(1-\text { tailed })\end{array}$ \\
\hline Medium & PH : PL & $0.65: 0.56$ & 248.50 & 0.000 \\
\hline low & Reject $\mathrm{H}_{0}$ & 0.003 \\
\hline
\end{tabular}

Table 6. Summary of Tests for the Effect of Interactions between Learning and School Level on the Improvement of Mathematical Problem Solving Ability

\begin{tabular}{|c|c|c|c|c|c|}
\hline Source & Sum of Squares & $\boldsymbol{d f}$ & Mean Squared & $\boldsymbol{F}$ & 11,42 \\
\hline Learning*School Level & 3.333 & 1 & 3.333 & 0.572 \\
\hline Total & 139262.000 & 120 & & \\
\hline
\end{tabular}




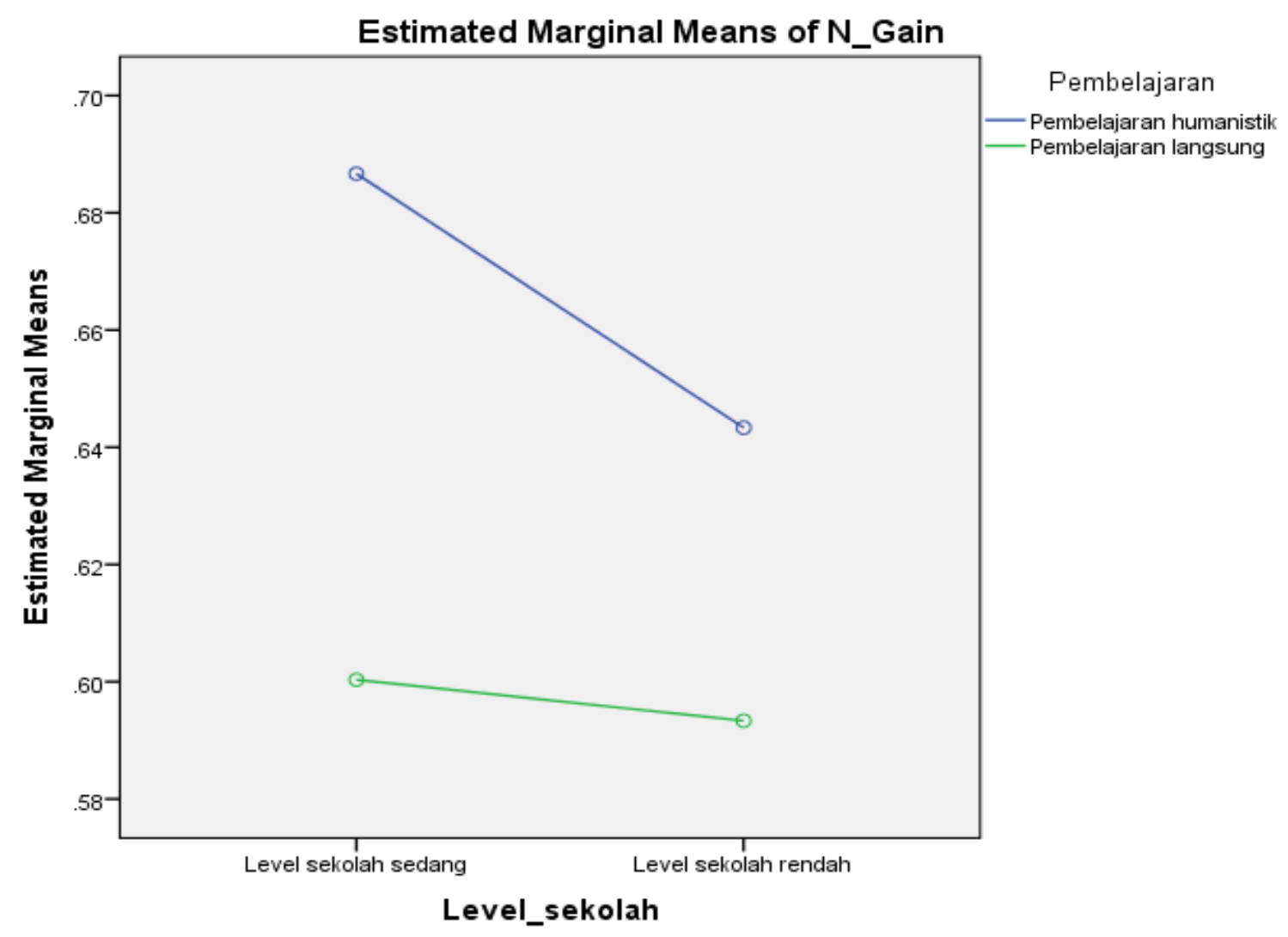

Figure 1. Effect of Interaction between Learning Groups and School Level on Improved Mathematical Problem Solving Ability

From Figure 1, information is obtained that the humanistic approach has a greater influence than direct learning on improving problem-solving abilities at the medium and low school levels. Thus it can be concluded that humanistic learning can improve students' problem-solving abilities. Besides, there is no interaction between the two lessons. This can be seen from the absence of a line that intersects the two.

\subsection{Student Attitudes toward Humanistic Approach}

Students' attitudes towards learning with a humanistic approach analyzed were descriptions of interest with indicators showing a preference for learning mathematics with a humanistic approach, student activity with indicators showing seriousness by showing activities during the learning process with a humanistic approach. The results of the distribution of attitude scales and scores for each alternative answer can be seen in full in Table 7 .

From the distribution of students' answers in Table 7, it can be seen that students generally respond positively or are interested in the humanistic approach to learning methods. Of the 30 students, it turned out that 27 (90\%) students stated that they were happy with the learning method. The learning provided was easier to understand. Only $3(10 \%)$ students still found it difficult to learn mathematics even though they had followed the method.

To find out activities during the learning process with a humanistic approach are stated in statements number 8,10 , 15,18 , and 21 , of the 30 students who stated that the learning method with a humanistic approach encourages students to exchange ideas with friends as many as 34 $(92 \%)$ students, who stated that learning with a humanistic approach made them dare to express their opinions both in front of the class and in groups of $27(90 \%)$ students. As many as $24(80 \%)$ students stated that learning with a humanistic approach made them able to concentrate well. Students who feel that learning with a humanistic approach confuses as many as $3(10 \%)$ students.

From this discussion, it can be concluded that students' attitudes towards learning with a humanistic approach indicate a positive attitude. Another variable that shows students' positive attitude is seen from the seriousness and enthusiasm of students in participating in learning and discussions. 
Table 7. Students' Attitudes towards Learning with a Humanistic Approach

\begin{tabular}{|c|c|c|c|c|c|c|c|}
\hline \multirow{2}{*}{ student attitude } & \multirow{2}{*}{ Description and Indicators } & \multirow{2}{*}{$\begin{array}{l}\text { question } \\
\text { number }\end{array}$} & \multirow{2}{*}{$\begin{array}{l}\text { the nature of the } \\
\text { statement }\end{array}$} & \multicolumn{4}{|c|}{ answer } \\
\hline & & & & SS & $\mathbf{S}$ & TS & STS \\
\hline \multirow{20}{*}{$\begin{array}{l}\text { Student attitudes } \\
\text { towards learning with a } \\
\text { humanistic approach }\end{array}$} & \multirow{10}{*}{$\begin{array}{l}\text { (Learning Method) Shows a } \\
\text { preference for learning } \\
\text { mathematics with a humanistic } \\
\text { approach }\end{array}$} & \multirow{2}{*}{9} & positive & 19 & 8 & 2 & 1 \\
\hline & & & percentage & $63 \%$ & $27 \%$ & $7 \%$ & $3 \%$ \\
\hline & & \multirow{2}{*}{11} & positive & 5 & 20 & 4 & 1 \\
\hline & & & percentage & $17 \%$ & $67 \%$ & $13 \%$ & $3 \%$ \\
\hline & & \multirow{2}{*}{12} & positive & 5 & 20 & 5 & 0 \\
\hline & & & percentage & $17 \%$ & $67 \%$ & $17 \%$ & $0 \%$ \\
\hline & & \multirow{2}{*}{13} & negative & 1 & 2 & 20 & 7 \\
\hline & & & percentage & $3 \%$ & $7 \%$ & $67 \%$ & $23 \%$ \\
\hline & & \multirow{2}{*}{16} & negative & 0 & 1 & 8 & 21 \\
\hline & & & percentage & $0 \%$ & $3 \%$ & $27 \%$ & $70 \%$ \\
\hline & \multirow{10}{*}{$\begin{array}{l}\text { (Student Activities) Show } \\
\text { seriousness by showing activities } \\
\text { during the learning process with a } \\
\text { humanistic approach }\end{array}$} & \multirow{2}{*}{8} & positive & 9 & 18 & 3 & 0 \\
\hline & & & percentage & $30 \%$ & $60 \%$ & $10 \%$ & 0 \\
\hline & & \multirow{2}{*}{10} & positive & 8 & 19 & 2 & 1 \\
\hline & & & percentage & $27 \%$ & $63 \%$ & $7 \%$ & $3 \%$ \\
\hline & & \multirow{2}{*}{15} & negative & 1 & 1 & 7 & 21 \\
\hline & & & percentage & $3 \%$ & $3 \%$ & $23 \%$ & $70 \%$ \\
\hline & & \multirow{2}{*}{18} & negative & 2 & 1 & 15 & 12 \\
\hline & & & percentage & $7 \%$ & $3 \%$ & $50 \%$ & $40 \%$ \\
\hline & & \multirow{2}{*}{21} & positive & 15 & 9 & 6 & 0 \\
\hline & & & percentage & $50 \%$ & $30 \%$ & $20 \%$ & $0 \%$ \\
\hline
\end{tabular}

\section{Conclusions}

From the data analysis and discussion of the research results described, the conclusions of this study are:

a). The overall achievement of the mathematical problem-solving ability of students who take learning with a humanistic approach is higher overall than students who take direct learning.

b). Increased mathematical problem-solving abilities of students who take the humanistic approach to learning are better than students who take direct learning at medium and low school levels. The best quality in improving students' mathematical problem-solving abilities in the two learning groups is at the medium school level.

c). There is no interaction between learning (humanistic approach, direct learning) and school level (moderate, low) on improving mathematical problem-solving abilities.

d). Learning with a humanistic approach raises a courageous, active, and creative attitude in students. It can work well among fellow students, especially in discovering new concepts through experiments, and trying to solve given questions, discussing with fellow groups. Students dare to put forward or propose questions to the teacher.

\section{Recommendation}

Mathematics is an essential subject and is at the core of education, stimulating students intellectually at various levels. However, students often feel anxious and are afraid of mathematics. As a result, students cannot understand mathematical concepts well and are unable to find solutions to mathematical problems they face. The humanistic approach is a need nowadays to see these students' condition; the students have lost their enthusiasm for learning and have also become intolerant and selfish. It is recommended that teachers use mathematics learning with a humanistic approach because humanistic education aims to provide a foundation for personal growth and development so that learning will continue throughout life independently. This study indicates that learning with a humanistic approach will allow teachers to make students enjoy the education provided without coercion and burden, offer higher levels of involvement and motivation to learn, and increase the ability to solve problems.

\section{REFERENCES}

[1] M. J. Simmers, "It's Not the Math They Hate," 2011. 
[2] OECD, PISA 2012 Results: Ready to Learn (Volume III), vol. III. 2013.

[3] National Association of Mathematics Advisors, "Five myths of mastery in mathematics," Math. Teach., no. 251, pp. 20 24, 2015.

[4] J. BOALER, "Ability and Mathematics: the mindset revolution that is reshaping education," Forum Fam. Plan. West. Hemisph., vol. 55, no. 1, p. 143, 2013.

[5] NCTM, Principles and Standards for School Mathematics. USA: Library of Congress Cataloguing-in-Publication Data, 2000 .

[6] H. Niemi, V. Harju, M. Vivitsou, K. Viitanen, J. Multisilta, and A. Kuokkanen, "Digital Storytelling for $21^{\text {st }}$-Century Skills in Virtual Learning Environments," Creat. Educ., vol. 05, no. 09, pp. 657-671, 2014.

[7] OECD, "Pisa 2015 Draft Collaborative Problem Solving Framework March 2013," 2015.

[8] M. Rohmah and S. Sutiarso, "Analysis problem solving in mathematical using theory Newman," Eurasia J. Math. Sci. Technol. Educ., 2018.

[9] S. Cernajeva, "Humanistic Approach to Teaching the Course in Mathematics," Bound. F. Probl. Comput. Simul., vol. 51, pp. 92-95, 2012.

[10] R. Haglund, "Using Humanistic Content and Teaching Methods to Motivate Students and Counteract Negative Perceptions of Mathematics," Humanist. Math. Netw. J., vol. 1, no. 27, 2004.
[11] A. Sharp, "Humanistic Approaches to Learning," Encycl. Sci. Learn., 2012.

[12] P. Chen and C. Schmidtke, "Humanistic elements in the educational practice at a United States sub-baccalaureate technical college," Int. J. Res. Vocat. Educ. Train., vol. 4, no. 2, pp. 117-145, 2017

[13] D. Parsons, "Humanist Learning Theory," wordpress.com, 2010. [Online]. Available: https://daparsons.files.wordpress .com/2013/07/humanist-learning-theory.pdf.

[14] A. P. Johnson, "Humanistic learning theory," Educ. Psychol. Theor. Learn. Hum. Dev., pp. 1-9, 2014.

[15] J. B. B. Arthur K. Ellis, Research on Educational Innovations, 5th Editio. Larchmont, NY: Routledge, 2016.

[16] C. Alacaci and M. Dogruel, "Solving a Stability Problem By Polya's Four Steps," Int. J. Electron. Mech. Mechatronics Eng., vol. 1, no. 1, 2010.

[17] J. Carson, "A Problem with Problem Solving: Teaching Thinking without Teaching Knowledge," Math. Educ., vol. 17, no. 2, pp. 7-14, 2006.

[18] J.-B. N. Nakin, "Creativity and Divergent Thinking in Geoetry Education," UNIVERSITY OF SOUTH AFRICA, 2003.

[19] D. Ary, L. C. Jacobs, and C. Sorensen, Introduction to Research in Education, 8 th. Canada: Wadsworth, 2010.

[20] D. E. Meltzer, "The relationship between mathematics preparation and conceptual learning gains in physics: A possible 'hidden variable' in diagnostic pretest scores," Am. J. Phys., vol. 70, no. 12, pp. 1259-1268, 2002. 